ORIGINAL PROF-2147

\title{
CONVERSION DISORDER;
}

\section{Childhood sexual abuse in patients, a descriptive study in in-patients of Tertiary Care psychiatric facility.}

Prof. Dr. Niaz Maqsood, Dr. Naeem-ullah Laghari, Miss Bushra Akram

ABSTRACT... Objective: The objective of the study was to find out association and pattern of childhood sexual abuse in patients presenting with conversion disorder. Study Design: A descriptive study. Place \& duration of study: The study was conducted in the Department of Psychiatry \& Behavioural Sciences, Bahawal Victoria Hospital \& Quaid-e-Azam Medical College, Bahawalpur from June, 2011 to December, 2011. Subjects \& Methods: The sample consisted of 60 Female in-patients with Conversion Disorder by purposive sampling. They were interviewed and results were analysed from the entries in a semi structured Performa. Results: Out of 60 patients, $34(57 \%)$ reported sexually abused in childhood and 26(43\%) not abused. There were 19(32\%) patients reported uncomfortable sexual talk, sexual touching, 9(15\%) reported attempted intercourse which was successful and 6(10\%) reported attempted for intercourse but failed in their aim. 14(23\%) patients abused by their relatives, 5(8\%) by Neighbours and strangers, 3(5\%) by their health caregivers, boyfriends and class fellows and $1(2 \%)$ by teachers. Conclusions: This study shows a positive association between severe sexual abuse (Uncomfortable talk, sexual touching, penetration or attempted penetration) in childhood and Conversion Disorder in adult life.

Key words: Sexual Abuse, Conversion Disorder

Article Citation

Maqsood N, Leghari N, Akram B. Conversion disorder; childhood sexual abuse in patients, a descriptive study in in-patients of tertiary care psychiatric facility. Professional Med J 2013;20(6): 981-987.

\section{INTRODUCTION}

Conversion a term introduced by Freud for a hypothetical mechanism by which psychological stress leads to (is converted into) physical symptoms and Conversion Disorder defined as a term for condition that may result from conversion: conditions that in the past were called hysteria ${ }^{1}$.

In the Diagnostic and Statistical Manual of Mental Disorders of the American Psychiatric Association, 4th edition (DSM-IV-TR), conversion disorders are included under the category Somatoform Disorders².

The International Classification of Diseases 10th revision (ICD-10) classifies as Dissociative (conversion) disorders, under the F44 category (Neurotic, stress-related and somatoform disorders).

Conversion disorders are a group of somatoform disorders which involve unexplained symptoms or deficits affecting voluntary motor or sensory functions. Pseudo-seizures, fainting spells, gait disturbances, tremors etc are common presenting symptoms ${ }^{4}$.
Somatoform Disorder suggesting a physical disorder for which there are no demonstrable organic findings or known Physiological mechanism, and for which there is strong evidence, or a strong presumption, that the symptoms are linked to psychological factors or conflicts $^{3}$.

"Sexual abuse" was defined as any pressure to engage in or any forced sexual contact before age 16, originally ranging from fondling to penetration ${ }^{5}$.

In 1896 Freud came to the conclusion that sexual molestation of his female patients during childhood and adolescence was responsible for the hysterical symptoms and personality traits exhibited later in life ${ }^{6}$.

Pierre Janet had emphasized the relation between conversion disorder and childhood trauma by the end of the 19th century. He viewed dissociation of cognitive, sensory, and motor processes as adaptive in the context of an overwhelming traumatic experience. Childhood sexual abuse may be related to more deleterious on long-term physical abuse ${ }^{7}$. 
Child sexual abuse is widely regarded as a cause of mental health problems in adult life. Childhood sexual abuse is considerably less common in males, with the ratio of female to male victims estimated to be as high as 12:1. There is also some evidence that childhood sexual abuse may be particularly pernicious in its effects and that it is more likely to predict the subsequent development of psychiatric illness than does sexual assault occurring in adulthood ${ }^{8}$.

Childhood trauma could be a precursor for these dissociative tendencies, since higher dissociation levels have been found in rape victims reporting childhood sexual abuse than in non abused rape victims ${ }^{9}$.

Among sexually abused female inpatients, physical neglect and witnessing sexual abuse or physical abuse were associated with higher levels of dissociative symptoms, but childhood stressors involving loss were not ${ }^{10}$.

Child sexual abuse is not randomly distributed through the population. It occurs more frequently in children from socially deprived and disorganised family backgrounds, ${ }^{11}$ Marital dysfunction, as evidenced by parental separation and domestic violence, ${ }^{12}$ poor family functioning, poor parent child attachment, lack of adequate care, single-parenthood, ${ }^{10}$ extreme poverty, low socioeconomic status and drug abuse in the family, is associated with higher risks of child sexual abuse ${ }^{13}$.

Abusers can be classified by their relationship to the child victim into three categories: family, acquaintances, or strangers. Sexual abuse is committed primarily by individuals known to the child, unlike the child molester stereotype that prevailed until the 1970s. In adult retrospective surveys, victims of abuse indicate that no more than $10 \%$ to $30 \%$ of offenders were strangers, with the remainder being either family members or acquaintances ${ }^{14}$.
In Pakistan there have been only few studies of childhood sexual abuse. In particular the relationship between childhood sexual abuse and Conversion disorder has rarely been addressed. The aim of the present study is an attempt to find out association and pattern of childhood sexual abuse in patients presenting with conversion disorder.

\section{MATERIAL AND METHODS}

The study was conducted in the Department of Psychiatry \& Behavioural Sciences, Bahawal Victoria Hospital, a teaching hospital affiliated with Quaid-eAzam Medical College, Bahawalpur. The Department offers in-patient and out-patient treatment services for Psychiatric Patients with a team of trained Psychiatrists and Psychologists.

The study included 60 female patients, who were admitted in the Psychiatry ward with symptoms of Conversion Disorder from June, 2011 to December, 2011. Only those female patients were included in this study who was reported childhood sexual abuse before age 16, had a permanent damaging effect on them. If the patients were suffering from any other psychiatric morbidity, drug abuse, organic brain syndromes and was not fulfilling the criteria of the Conversion Disorder were excluded from the study. All the patients were diagnosed according to the criteria of Diagnostic and Statistical Manual (DSM-IV) ${ }^{2}$ laid down by American Psychiatric Association 1994. Informed verbal consent was taken from the patients and then all the information collected on the semi structured proforma (Demographic sheet) by Structured Clinical Interview. Confidentiality was also ensured.

Each subject was asked whether or not during childhood he or she had been "physically or psychologically forced by anyone to engage in any unwanted sexual activity, sexually assaulted, or raped," e.g. Has anyone talked to you in a sexual way that made you feel uncomfortable? Has anyone touched you, or got you to touch them, in a sexual way 
without your consent? Has anyone had sexual intercourse with you without your consent? Subjects who responded positively to this question were then asked further questions relating to this activity (if they felt able to talk about the matter). Subjects were classified as having a history of childhood sexual abuse if they responded positively to the initial questions and subsequent questioning established a history of childhood sexual abuse ${ }^{15}$. The subjects were divided into three groups: Those who suffered by Uncomfortable sexual talk, Sexual touching or any sexual demand, those who were attempted for intercourse but unsuccessful and those who were attempted for intercourse and successful.

The data was analyzed using Statistical Package for Social Sciences (SPSS) version 10.0 for frequencies and percentages. The results were depicted in the form of tables \& summarized for age, locality, education, occupation, marital status, nature of sexual abuse and relation with abuser.

\section{RESULTS}

Table.1 shows Demographic Characteristics of subjects. Out of 60 subjects, majority of patients 26 $(43 \%)$ were $21-25$ years age group, $32(53 \%)$ belonged to rural area, $38(63 \%)$ single and $25(42 \%)$ students.

Tables II shows frequency of sexually abused patients. Out of 60 patients $34(57 \%)$ were sexually abused in childhood and 26(43\%) were not abused.

Tables III shows percentages of the Nature of Abuse. Out of 60 patients, 34(57\%) reported abused but nature of abuse was varying. Of these $34(57 \%)$ patients, 19(32\%) patients reported Uncomfortable Sexual talk, sexual touching or any sexual demand, $9(15 \%)$ those that had attempted intercourse by someone and that attempt successful but $6(10 \%)$ unsuccessful attempt.

\begin{tabular}{|c|c|c|}
\hline Characteristics & $\begin{array}{c}\text { Abused } 34(57 \%) \\
\text { Frequency (\%) }\end{array}$ & $\begin{array}{c}\text { Not Abused } \\
26(43 \%) \\
\text { Frequency (\%) }\end{array}$ \\
\hline \multicolumn{3}{|c|}{ Age Groups } \\
\hline $16-20$ & $12(35 \%)$ & 7 (27\%) \\
\hline $21-25$ & 18 (53\%) & $8(31 \%)$ \\
\hline $26-30$ & $1(3 \%)$ & $5(19 \%)$ \\
\hline $31-35$ & $3(9 \%)$ & $6(23 \%)$ \\
\hline \multicolumn{3}{|c|}{ Locality } \\
\hline Rural & $20(59 \%)$ & $12(46 \%)$ \\
\hline Urban & $14(41 \%)$ & $14(54 \%)$ \\
\hline \multicolumn{3}{|c|}{ Marital Status } \\
\hline Single & $24(71 \%)$ & $14(54 \%)$ \\
\hline Married & $9(26 \%)$ & $10(38 \%)$ \\
\hline Divorced & $1(3 \%)$ & $2(8 \%)$ \\
\hline \multicolumn{3}{|c|}{ Education } \\
\hline Uneducated & $7(21 \%)$ & $3(12 \%)$ \\
\hline Primary & $3(9 \%)$ & $4(15 \%)$ \\
\hline Middle & $2(6 \%)$ & $1(4 \%)$ \\
\hline Matric & $5(15 \%)$ & $4(15 \%)$ \\
\hline F.A / F.Sc & $3(9 \%)$ & $4(15 \%)$ \\
\hline B.A / B.Sc & $3(9 \%)$ & $5(19 \%)$ \\
\hline M.A / M.Sc & $4(12 \%)$ & $5(19 \%)$ \\
\hline MBBS & $3(9 \%)$ & - \\
\hline MBA & $3(9 \%)$ & - \\
\hline ACCA & $1(3 \%)$ & - \\
\hline \multicolumn{3}{|c|}{ Occupation } \\
\hline Unemployed & $8(27 \%)$ & $6(23 \%)$ \\
\hline Student & $16(47 \%)$ & $9(35 \%)$ \\
\hline House Wife & $8(24 \%)$ & $8(31 \%)$ \\
\hline Employed & $2(6 \%)$ & $3(12 \%)$ \\
\hline
\end{tabular}

Table-I. Demographic subject characteristics $(n=60)$ 


\begin{tabular}{|c|c|}
\hline Sexual Abused & Frequency (\%) \\
\hline Not Abused & $26(43 \%)$ \\
\hline Sexual Abused & $34(57 \%)$ \\
\hline & Table-\| \\
\hline
\end{tabular}

\begin{tabular}{|l|c|}
\hline \multicolumn{1}{|c|}{ Nature of Abused } & Frequency (\%) \\
\hline $\begin{array}{l}\text { Uncomfortable sexual talk, touch or any } \\
\text { sexual demand ect. }\end{array}$ & $19(32 \%)$ \\
\hline Attempted for intercourse and successful & $9(15 \%)$ \\
\hline $\begin{array}{l}\text { Attempted for intercourse but } \\
\text { unsuccessful }\end{array}$ & $6(10 \%)$ \\
\hline
\end{tabular}

Table-III

Table IV shows percentages of the Relation with Abuser and majority of patients 14(23\%) were abused by their relatives.

\begin{tabular}{|c|c|}
\hline Abused by & Frequency (\%) \\
\hline Relatives & $14(23 \%)$ \\
\hline Neighbour & $5(8 \%)$ \\
\hline Stranger & $5(8 \%)$ \\
\hline Health caregiver & $3(5 \%)$ \\
\hline Class fellow & $3(5 \%)$ \\
\hline Boy Friend & $3(5 \%)$ \\
\hline Teacher & $1(2 \%)$ \\
\hline Table-IV. Relation with abuser
\end{tabular}

\section{DISCUSSION}

In our research, amongst females presenting with conversion disorder, about $57 \%$ had to face some form of sexual abuse in the childhood. This was in line with another research by Cheasty, et al., ${ }^{16}$ where the incidence of sexual abuse was $67 \%$ however other researches reported sexual abuse $82 \%^{17}, 57 \%^{18}$ and $49 \%{ }^{19}$.
The present research focused on female population. This was in keeping with Chu JA, et al., ${ }^{17}$ Cheasty, et al., ${ }^{16}$ and Chu JA, et al., ${ }^{20}$. All these studies observed only the females. Girls are victimized more often than boys. Boys are abused at one-third to one-half the rate of girls, according to adult retrospective studies ${ }^{21}$.

In this study, subjects were sexually abused before age of 16 years. But majority of the patients (43\%) presented with conversion disorder later at 21-25 years of age group. This is in accordance with Bifulco A, who conducted a study on women ( $N=286), 64 \%$ of women who reported childhood sexual abuse before age 17 years, but they were diagnosed with Conversion Disorder in adult $\mathrm{age}^{22}$. Finkelhor and Baron also found sexual abuse between the ages of 7 and $13^{23}$. In a random sample of 314 women selected from Dunedin, New Zealand, $20.7 \%$ of women gave a history of childhood sexual abuse before age $12^{24}$.

In this study, 23\% patients were abused by their relatives, $8 \%$ by Neighbors and strangers, $5 \%$ by their health caregivers, boyfriends and class fellows and $2 \%$ by their teachers. This is in accordance with other researches. In some adult retrospective surveys, victims of abuse indicate that no more than $10 \%$ to $30 \%$ of offenders were strangers, with the remainder being either family members or acquaintances ${ }^{14}$. One study by Chu JA et al., shows $28 \%$ abused by family, $8 \%$ by strangers ${ }^{20}$.

Present research revealed that about $5 \%$ of the abusers were from health caregivers. They included Dispenser, Quaks, Hakeem and Doctors etc. This is in accordance with other studies. In Ontario, Canada, in the 80 s, $25 \%$ of the health care providers who had been legally charged with patient sexual contact were psychiatrists $^{25} \& 7.3 \%$ were physicians ${ }^{26}$. One surveys of psychiatrists revealed that $7 \%$ to $10 \%$ reported previous sexual contact with patients ${ }^{25}$. The higher incidence of involvement of health caregiver providers in our setting seems to be due to our peculiar culture. 
This may be due to the factor that peoples have usually blind faith in their caregiver in our traditions.

In this study, 32\% patients reported uncomfortable sexual talk, sexual touching, $15 \%$ reported attempted intercourse which was successful and $10 \%$ reported attempted for intercourse but failed in their aim. The most recent Adult Psychiatric Morbidity Survey in England (APMS 2007) ${ }^{27}$ has detailed information about levels of childhood sexual abuse. Nonconsensual sexual intercourse before the age of 16 was reported by $1.9 \%$ of the sample, unwanted sexual touching by $8.2 \%$, and uncomfortable sexual talk by $10.3 \%^{28}$. One study by Cheasty, et al., shows Touch/nonpenetrative $11 \%$, Attempted intercourse $19 \%$, intercourse $47 \%{ }^{16}$. The difference of present study with other researches may be due to the factor that in Pakistan girls are not that much confident in childhood and they can easily be harassed.

\section{LIMITATIONS \& SUGGESTIONS}

There are some limitations in this study. It included the female population only. Moreover the sample size was small.

There are also certain suggestions. Further research with large sample size and inclusion of male gender may be required. Appropriate sexual education and guidance should be provided to the families to prevent such incidence. Moreover the role of abuse should not be neglected in patients presenting with unexplained medical symptoms.

\section{CONCLUSIONS}

We concluded that a significant association exists between childhood sexual abuse and increased psychopathology as an adult. This study shows a positive association between sexual abuse (Uncomfortable talk, sexual touching, penetration or attempted penetration) in childhood and Conversion Disorder in adult life.

\section{Copyright@ 15 Aug, 2013}

\section{REFERENCES}

1. Gelder $M$, Harrison $P$, Cowen P. Somatoform and dissociative disorders. In: Shorter Oxford textbook of Psychiatry. 5th ed. Oxford University Press. 2006; pp 204.

2. Diagnostic and Statistical Manual of Mental Disorders. 4th ed (TR). Washington D.C; American Psychiatric Association, 1994; pp 445-69.

3. The International Statistical Classification of Diseases and Health Related Problems, 10th Revision. 2nd ed. World Health Organization, 2006.

4. Steffanson JG, Messina JA, Meyerowitz S. Hysterical neurosis, conversion type: clinical and epidemiological consideration. Acta Psychiatr Scand. 1976; 53: 110-38.

5. Roelofs K, Keijsers GP, Hoogduin KA, Näring GW. Childhood Abuse in Patients with Conversion Disorder. Am J Psychiatry. 2002; 159 (11):1908-13.

6. LaBarbera JD, Dozier JE. Hysterical seizures: the role of sexual exploitation. Psychosomatics.1980; 21(11): 897-903

7. Putnam FW. Pierre Janet and modern views of dissociation. J Trauma Stress. 1989; 2: 413-429.

8. Weiss EL, Longhurst JG, Mazure CM. Childhood sexual abuse as a risk factor for depression in women: psychosocial and neurobiological correlates. Am J Psychiatry. 1999; 156(6):816-28.

9. Dancu CV, Riggs DS, Hearst-lkeda DE, Shoyer BG, Foa $E B$ : Dissociative experiences and posttraumatic stress disorder among female victims of criminal assault and rape. J Trauma Stress. 1996; 9:253-267.

10. Draijer N, Langeland W. Childhood trauma and perceived parental dysfunction in the etiology of dissociative symptoms in psychiatric inpatients. Am J Psychiatry. 1999; 156(3): 379-85.

11. Beitchman JH, Zucker KJ, Hood JE, da Costa GA, Akman D. A review of the short-term effects of child sexual abuse. Child Abuse and Neglect. 1991; 15: 53756. 
12. Mullen PE, Martin JL, Anderson JC, Romans SE, Herbison GP. The long-term impact of the physical, emotional and sexual abuse of children: a community study. Child Abuse and Neglect. 1996; 20: 7-22.

13. Mullen PE, Fleming J. Long-term Effects of Child Sexual Abuse. Child Abuse Prevention. 1998; 9.

14. Finkelhor D, Hotaling G, Lewis IA, Smith C. Sexual abuse in a national survey of adult men and women: Prevalence, characteristics, and risk factors. Child Abuse \& Neglect. 1990; 14:19-28.

15. Mulder RT, Beautrais AL, Joyce PR, Fergusson DM. Relationship between dissociation, childhood sexual abuse, childhood physical abuse, and mental illness in a general population sample. Am J Psychiatry. 1998; 155(6):806-11.

16. Cheasty M, Clare AW, Collins. Relation between sexual abuse in childhood and adult depression: case-control study. BMJ. 1998; 316(7126): 198201.

17. Chu JA, Frey LM, Ganzel BL, Matthews JA. Memories of childhood abuse: Dissociation, amnesia, and corroboration. Am J Psychiatry. 1999; 156(5): 74955 .

18. Bebbington P, Jonas S, Kuipers E, King M, Cooper C, Brugha $\mathrm{T}$, Meltzer $\mathrm{H}$, McManus $\mathrm{S}$, Jenkins $\mathrm{R}$. Childhood sexual abuse and psychosis: data from a cross-sectional national psychiatric survey in England. Br J Psychiatry. 2011; 199: 29-37.

19. Romans SE, Martin JL, Morris E, Herbison GP. Psychological defense styles in women who report childhood sexual abuse: a controlled community study. Am J Psychiatry. 1999; 156(7):1080-5.
20. Chu JA, Dill DL. Dissociative symptoms in relation to childhood physical and sexual abuse. Am J Psychiatry. 1990; 147(7): 887-92.

21. Finkelhor D. Current Information on the Scope and Nature of Child Sexual Abuse. Sexual Abuse of Children. 1994; 4(2): 31-53.

22. Bifulco A, Brown GW, Adler Z: Early sexual abuse and clinical depression in adult life. Br J Psychiatry. 1991; 159:115-122.

23. Finkelhor D, Baron L. High-risk children. In A sourcebook on child sexual abuse. D. Finkelhor, ed. Beverly Hills, CA: Sage, 1986; 60-88.

24. Mullen PE, Martin JL, Anderson JC, Romans SE, Herbison GP: Childhood sexual abuse and mental health in adult life. Br J Psychiatry.1993; 163:72132.

25. Rapp MS. Sexual misconduct. CMAJ. 1987; 137(3):193-4.

26. Luepker ET. Effects of practitioners' sexual misconduct: a follow-up study. J Am Acad Psychiatry Law. 1999; 27(1):51-63.

27. McManus S, Meltzer $\mathrm{H}$, Brugha T, Bebbington $\mathrm{P}$, Jenkins R. Adult Psychiatric Morbidity in England, 2007: Results of a Household Survey. NHS Information Centre, 2009.

28. Bebbington PE, Jonas S, Brugha T, Meltzer H, Jenkins $R$, Cooper C. Child sexual abuse reported by an English national sample: characteristics and demography. Soc Psychiatry Psychiatr Epidemiol. 2011; 46: 255-62. 


\section{AUTHOR(S):}

1. PROF. DR. NIAZ MAQSOOD

MBBS, DPM, MCPS, FCPS

Head Department of Psychiatry \& Behavioural Sciences,

Bahawal Victoria Hospital, Bahawalpur.

2. DR. NAEEM-ULLAH LAGHARI

MBBS, DPM, FCPS

Assistant Professor

Department of Psychiatry \& Behavioural Sciences, Nishtar Hospital, Multan.

3. MISS BUSHRA AKRAM

Clinical Psychologist,

Department of Psychiatry \& Behavioural Sciences,

Nishtar Hospital Multan.

\section{Correspondence Address:}

Prof. Dr. Niaz Maqsood

Department of Psychiatry \& Behavioural Sciences,

Bahawal Victoria Hospital, Bahawalpur

niazmaqsood@hotmail.com

\section{PREVIOUS RELATED STUDIES}

Niaz Maqsood, Bushra Akram, Wajid Ali, PATIENTS WITH CONVERSION DISORDER; PSYCHO-SOCIAL STRESSORS AND LIFE EVENTS (Original) Prof Med Jour 17(4) 715-720 Oct, Nov, Dec 2010.

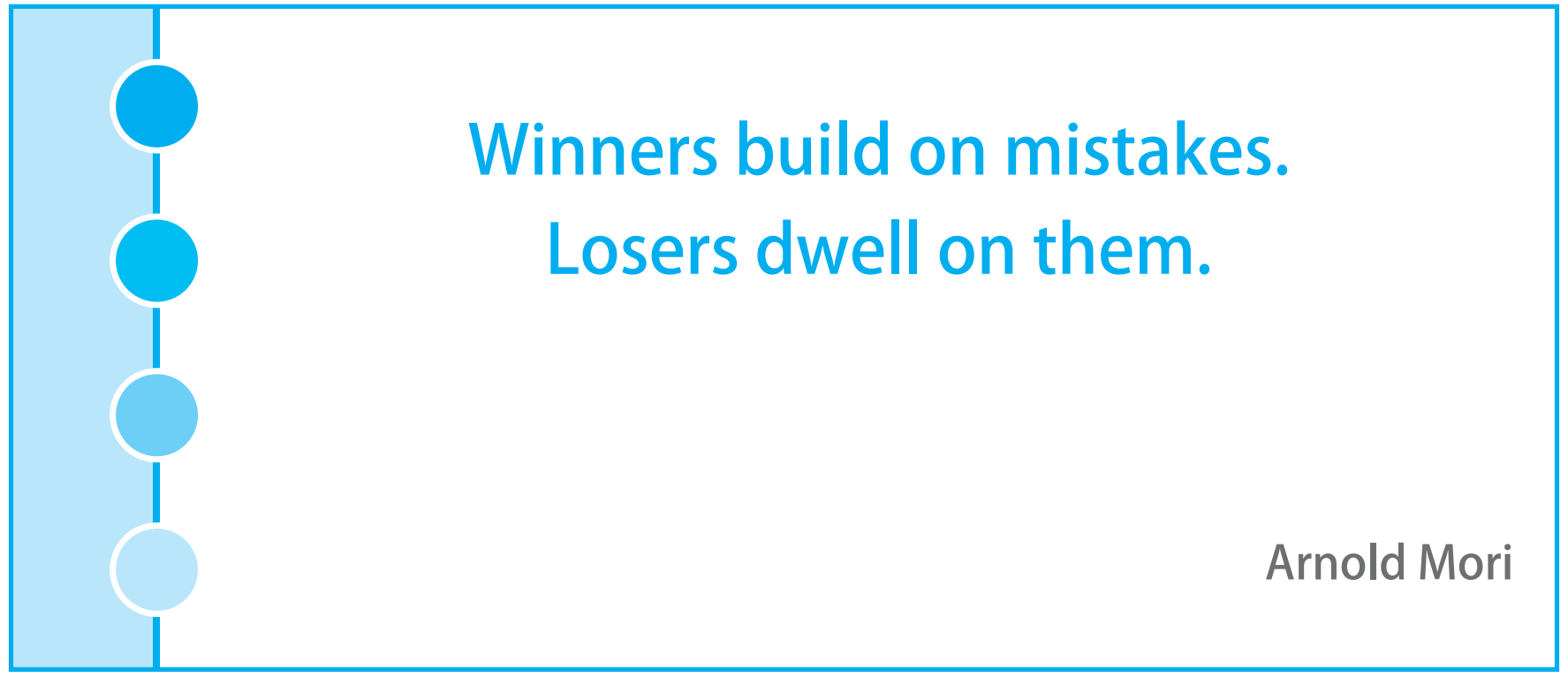

